\title{
D-GALACTOSE CATABOLISM IN PENICILLIUM CHRYSOGENUM: EXPRESSION ANALYSIS OF THE STRUCTURAL GENES OF THE LELOIR PATHWAY
}

\author{
Ágota JónÁs, Erzsébet FeKete, Zoltán NÉMeth, \\ Michel Flipphi and LeVente Karaffa* \\ Department of Biochemical Engineering, Faculty of Science and Technology, University of Debrecen, \\ H-4032, P.O. Box 64, Debrecen, Hungary \\ (Received: January 11, 2016; accepted: January 20, 2016)
}

\begin{abstract}
In this study, we analyzed the expression of the structural genes encoding the five enzymes comprising the Leloir pathway of D-galactose catabolism in the industrial cell factory Penicillium chrysogenum on various carbon sources. The genome of $P$. chrysogenum contains a putative galactokinase gene at the annotated locus Pc13g10140, the product of which shows strong structural similarity to yeast galactokinase that was expressed on lactose and D-galactose only. The expression profile of the galactose-1-phosphate uridylyl transferase gene at annotated locus Pc15g00140 was essentially similar to that of galactokinase. This is in contrast to the results from other fungi such as Aspergillus nidulans, Trichoderma reesei and $A$. niger, where the ortholog galactokinase and galactose-1-phosphate uridylyl transferase genes were constitutively expressed. As for the UDP-galactose-4-epimerase encoding gene, five candidates were identified. We could not detect Pc16g12790, Pc21g12170 and Pc20g06140 expression on any of the carbon sources tested, while for the other two loci (Pc21g10370 and Pc18g01080) transcripts were clearly observed under all tested conditions. Like the 4-epimerase specified at locus Pc21g10370, the other two structural Leloir pathway genes - UDP-glucose pyrophosphorylase (Pc21g12790) and phosphoglucomutase (Pc18g01390) - were expressed constitutively at high levels as can be expected from their indispensable function in fungal cell wall formation.
\end{abstract}

Keywords: Penicillium chrysogenum - lactose - D-galactose - Leloir pathway

\section{INTRODUCTION}

Lignocellulosic plant biomass is the most abundantly available organic raw material in nature. It is composed of cellulose, hemicellulose and pectin (recently reviewed in [8]). Hemicellulose can further be divided into three principal classes of polymers: xylan, mannan and xyloglucan [10]. D-galactose (NB. The C-4 epimer of D-glucose) is the only constituent monosaccharide common to all three classes, and is also present in important pectic polymers [33]. In depth knowledge about microbial enzyme systems involved in D-galactose release from plant biomass and its subsequent uptake and catabolism is of considerable industrial and environmental interest [4].

\footnotetext{
*Corresponding author; e-mail address: karaffa.levente@science.unideb.hu
} 
Ascomycete filamentous fungi are traditionally deemed superior to any other group of microorganisms in the biodegradation of lignocellulose due to their broad range of plant cell wall degrading enzyme activities and their protein secretion capabilities. Many of these fungal enzymes are operational under extreme environmental and industrial cultivation conditions such as high temperature, extremes of $\mathrm{pH}$, high salt concentrations or high pressure. Strains of Penicillium chrysogenum (species complex P. chrysogenum sensu lato, phylogenetic species $P$. rubens - [21]) have been exploited and continuously improved for the industrial production of penicillin and structurally related antibiotics from the Second World War onwards (for a recent review, see [31]). More recently, they are increasingly appreciated as efficient production platforms for a variety of hydrolysing enzyme cocktails of fungal origin on cheap agro-industrial residues and (other) abundantly available plant matter [36]. Nevertheless, little is known about the downstream metabolism of D-galactose and other monomeric lignocellulose contents fueling this widely applied fungal cell factory.

The Leloir pathway of D-galactose catabolism (Fig. 1) is ubiquitous in prokaryotic and eukaryotic cells (for a review, see [19]). It is comprised of an ATP-dependent galactokinase (EC 2.7.1.6) that catalyzes the formation of D-galactose-1-phosphate, which is subsequently converted to UDP-galactose by D-galactose-1-phosphate uridylyl transferase (EC 2.7.7.12) using UDP-glucose as the donor and yielding D-glucose

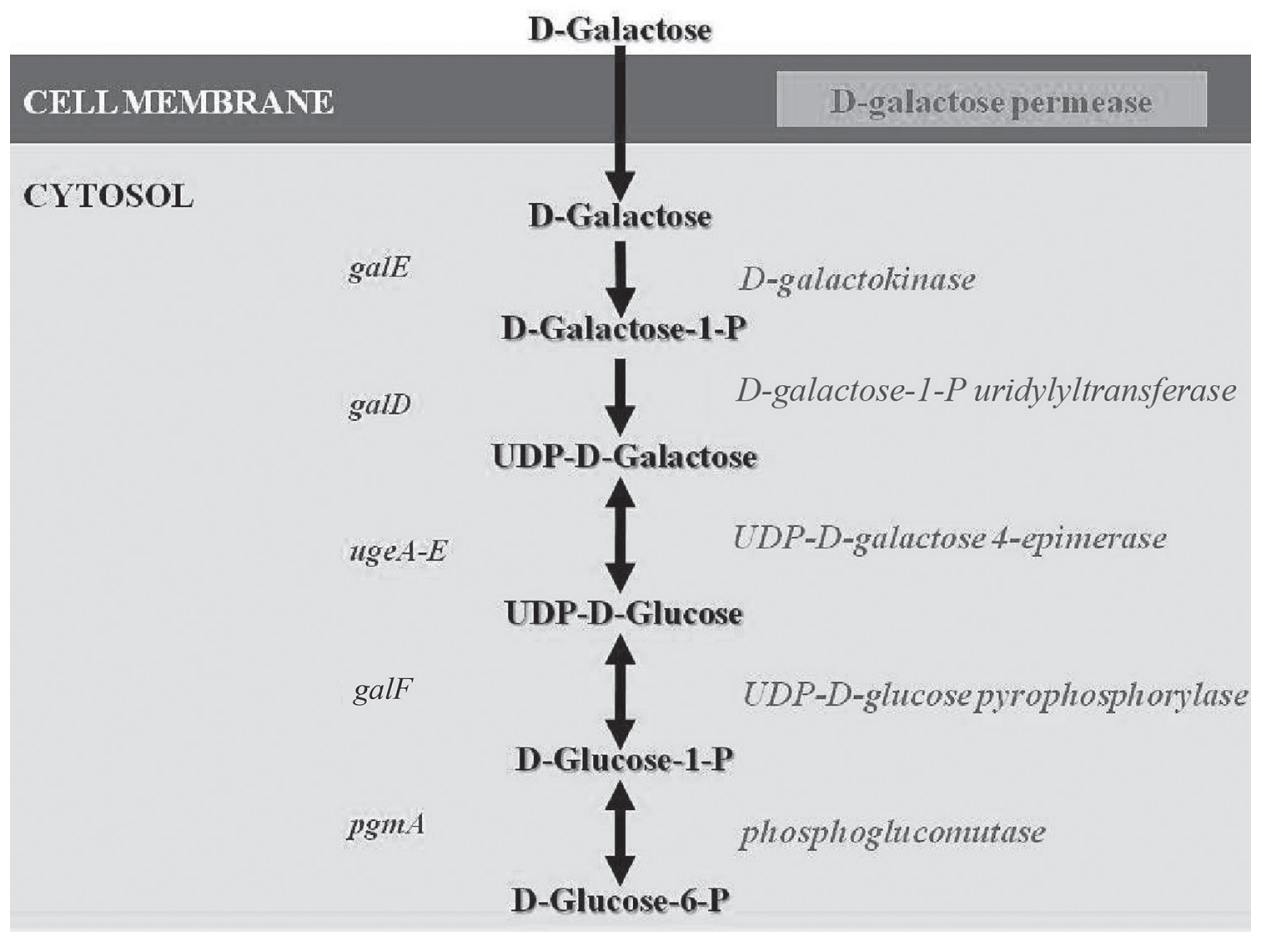

Fig. 1. Schematic representation of the Leloir pathway 
1-phosphate as the second product. Next, UDP-galactose is epimerized into UDPglucose by UDP-galactose-4-epimerase (EC 5.1.3.2) to recycle the co-factor. To complete the catabolisation of the D-galactose carbon source, UDP-glucose and glucose1-phosphate are interconverted by UDP-glucose pyrophosphorylase (EC 2.7.7.9) as glucose-1-phosphate feeds into mainstream metabolism after conversion into glucose6-phosphate, a key primary metabolite, by phosphoglucomutase (EC 5.4.2.2). However, on any other carbon source but D-galactose, the last three enzymes of the Leloir catabolic route work in the opposite, anabolic direction to produce the sugar nucleotides UDP-glucose and UDP-galactose from glucose-6-phosphate.** They are essential, uridylylated monomeric precursors of major fungal cell wall components, like beta-1,3-glucan, alpha-1,3-glucan and galactofuranose-containing glycans (for a review on the fungal cell wall, see [18]). A parallel anabolic Leloir route produces the uridylylated aminosugars UDP- $N$-acetylglucosamine and UDP- $N$-acetylgalactosamine from fructose-6-phosphate, ammonium and acetyl-CoA, using functionally similar phosphomutase, pyrophosphorylase and 4-epimerase activities encoded by other genes (for a review on UDP- $N$-acetylglucosamine biosynthesis in yeast, see [28]; for its epimerization to UDP- $N$-acetylgalactosamine, see [11]). These aminosugar nucleotides are essential precursors for, among others, the biosynthesis of chitin, chitosan and galactosaminogalactan components of filamentous fungal cell walls.

As part of a community-wide effort to curate, correct and update the automated gene annotation of the Aspergillus nidulans genome sequences [40], we previously identified the (putative) structural genes of the Leloir pathway of D-galactose metabolism in nine species of Aspergillus [17]. Aspergillus is the sister genus of Penicillium in the family of the Aspergillaceae [22] comprizing several hundred species including fungi widely used in the fermentation industry such as $A$. niger and A. oryzae, the opportunistic human pathogen $A$. fumigatus and the genetic model $A$. nidulans. For the current project, we mined the potential P. chrysogenum functional homologs of those five Aspergillus genes from publicly accessible DNA databases. We report here on their expression profiles on lactose - the main carbohydrate in the profuse dairy residue whey, often used to cultivate $P$. chrysogenum on industrial scale - and the monosaccharides most abundantly present in plant cell wall biomass, D-galactose, D-glucose, D-xylose and L-arabinose.

\section{MATERIALS AND METHODS}

\section{Strain and cultivation conditions}

P. chrysogenum NRRL 1951 used in this work was isolated from nature [34] and is the parent strain from which the large majority of industrial penicillin producers have been derived [30]. Minimal Medium (MM) was formulated as described previ-

\footnotetext{
**In 1970, the Argentine biochemist Luis Federico Leloir (1906-1987) received the Nobel Prize for Chemistry for his discovery of sugar nucleotides and their role in the biosynthesis of carbohydrates.
} 
ously [20] with sodium nitrate as sole nitrogen source. Carbon sources (i.e., sugars or glycerol) were used at concentrations up to $1 \%$ (w/v or v/v for glycerol). Supplements were added from sterile stock solutions. Cultures were inoculated with $5 \times 10^{6}$ $P$. chrysogenum conidia per $\mathrm{ml}$ of medium. Media inoculated with conidia also contained $0.01 \%(\mathrm{w} / \mathrm{v})$ peptone while growth media used after transfer of pregrown mycelia was completely synthetic. Shake flask cultures were incubated at $28{ }^{\circ} \mathrm{C}$ in $500 \mathrm{~mL}$ Erlenmeyer flasks containing $100 \mathrm{ml}$ of medium in a rotary shaker (Infors, Bottmingen, Switzerland) at 200 revolutions per minute (rpm).

Bioreactor cultures (henceforth referred to as fermentations) were inoculated with the harvested and washed mycelial biomass of $200 \mathrm{ml} \mathrm{MM} / \mathrm{glycerol}$-grown cultures. Fermentations were carried out as described earlier [24].

The yield coefficient $\left(\mathrm{Y}_{\mathrm{x} / \mathrm{s}}\right)$ was calculated as the ratio of the maximal concentration of biomass achieved during fermentation and the initial carbon source concentration. Specific growth rates $\left(\mathrm{m} ; \mathrm{h}^{-1}\right)$ were calculated from the increased dry cell weight during the time lapsed until carbon source exhaustion.

For induction experiments, replacement cultures were used for which mycelia were pregrown for $36 \mathrm{~h}$ in minimal medium containing $1 \%(\mathrm{v} / \mathrm{v})$ glycerol as carbon source, and harvested by filtration on a sintered glass funnel. After a thorough wash with cold sterile water, biomass was transferred to flasks with fresh MM containing the various carbon sources tested. For transcript analysis, samples were taken 4, 8, 12 and $24 \mathrm{~h}$ after the transfer of mycelia.

\section{Genomic DNA and total RNA isolation}

Mycelia were harvested by filtration over Miracloth (Calbiochem, San Diego, CA, USA) and thoroughly washed with cold sterile distilled water. Excess liquid was removed by squeezing between paper sheets and the biomass was quickly frozen in liquid nitrogen. For nucleic acid isolation, frozen biomass was ground to dry powder using liquid nitrogen-chilled mortar and pestle. Genomic DNA was extracted using NucleoSpin Plant II, whereas total RNA was isolated with NucleoSpin RNA Plant (both kits from Macherey-Nagel, Düren, North Rhine-Westphalia, Germany).

\section{Northern blot analysis}

Standard procedures [37] were applied for the quantification, denaturation, gel separation and nylon blotting of total RNA, and the subsequent hybridization of the resultant membranes with gene-specific probes. Agarose gels were charged with $5 \mathrm{mg}$ RNA per slot. Probes were digoxigenin-labeled using the PCR DIG Probe Synthesis Kit primed with gene-specific oligonucleotides (listed in Table 1) off P. chrysogenum NRRL 1951 genomic DNA. Gene-specific hybridization was visualized with LumiFilm Chemiluminescent Detection film. All transcript analyses were independently repeated at least twice. 


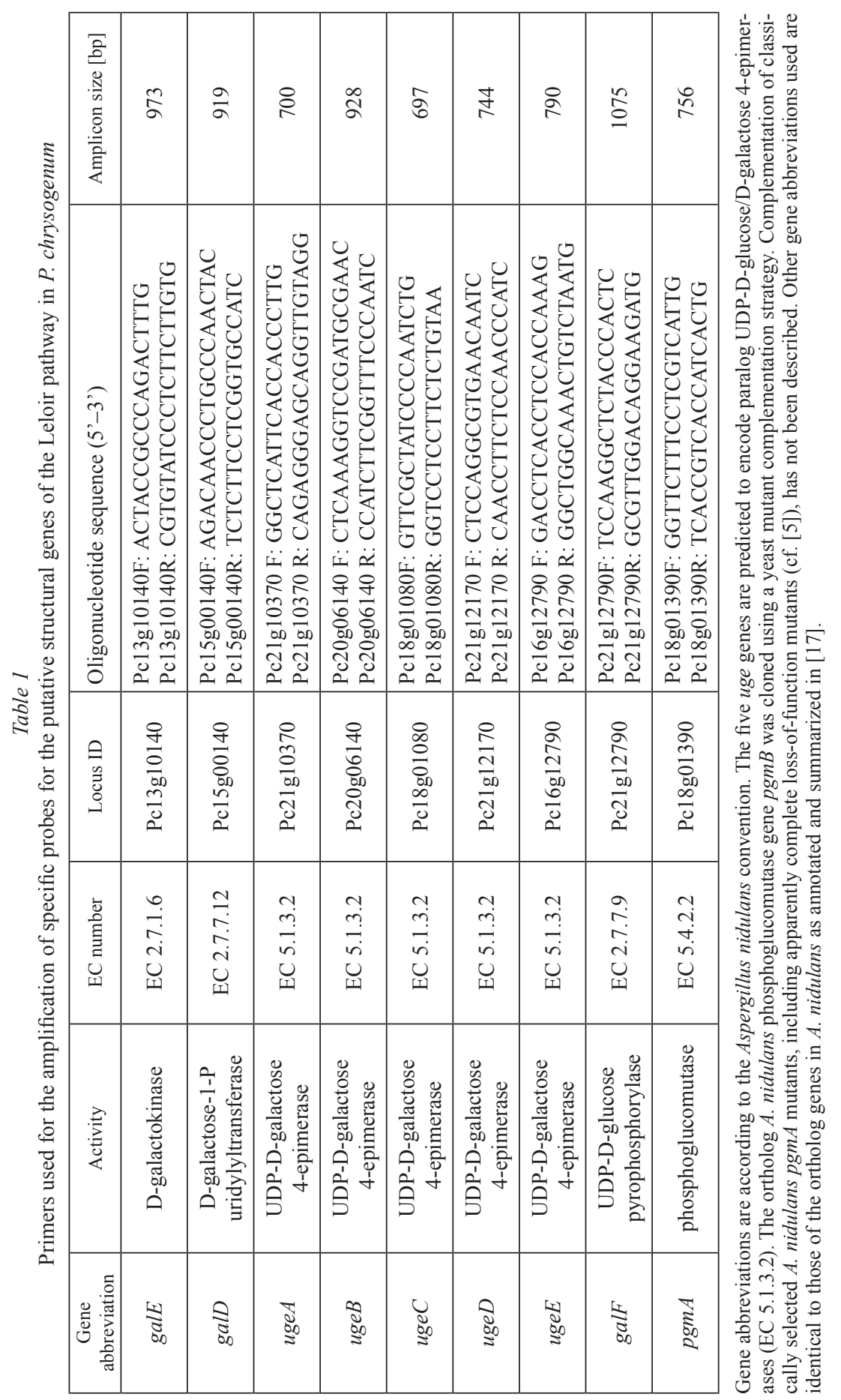




\section{Bioinformatics}

The first published P. chrysogenum whole genome sequences are from the low penicillin titre strain Wisconsin 54-1255, a direct laboratory descendent of NRRL 1951. The non-redundant nucleotide (nt/nr) database of the National Center for Biotechnology Information (www.ncbi.nlm.nih.gov) were screened with TBLASTN [2] using Saccharomyces cerevisiae galactokinase, Escherichia coli galactose-1-phosphate uridylyl transferase, A. nidulans UDP-galactose-4-epimerase, UDP-glucose pyrophosphorylase and phosphoglucomutase proteins as queries, and gene models were manually deduced from mined genomic DNA contigs. We found five structural paralogs for UDP-galactose-4-epimerase. All the genes thus obtained were essentially identical to those mined from five other $P$. chrysogenum strains (including a derivate of the early production strain P2, also in the NRRL 1951 pedigree) whose genome sequences are accessible at NCBI's whole genome shotgun contig (WGS) database.

\section{Galactokinase enzyme assay}

Ten $\mathrm{ml}$ of culture broth were withdrawn in triplicates from the shake-flasks $10 \mathrm{~h}$ and $24 \mathrm{~h}$ after transfer of mycelia. After suction filtration, the biomass on the filter was thoroughly washed with $0.1 \mathrm{M}$ sodium phosphate buffer, $\mathrm{pH}$ 7.6. The mycelia were then resuspended in $10 \mathrm{ml}$ of the same buffer and homogenized in a precooled PotterElvehjem glass homogenizer in continuation. The fresh cell-free extract was centrifuged at $8.500 \times \mathrm{g}\left(5 \mathrm{~min}, 4^{\circ} \mathrm{C}\right)$, and the supernatant immediately used to assay galactokinase activity. The assay was described earlier in $[13,14]$. In short, the concentration of galactose-1-phosphate in a reaction mixture containing $10 \mathrm{mM}$ ATP, $20 \mathrm{mM}$ D-galactose, $10 \mathrm{mM} \mathrm{MgSO}_{4}$, and $0.7 \mathrm{ml}$ cell-free extract in a $0.1 \mathrm{M}$ phosphate buffer

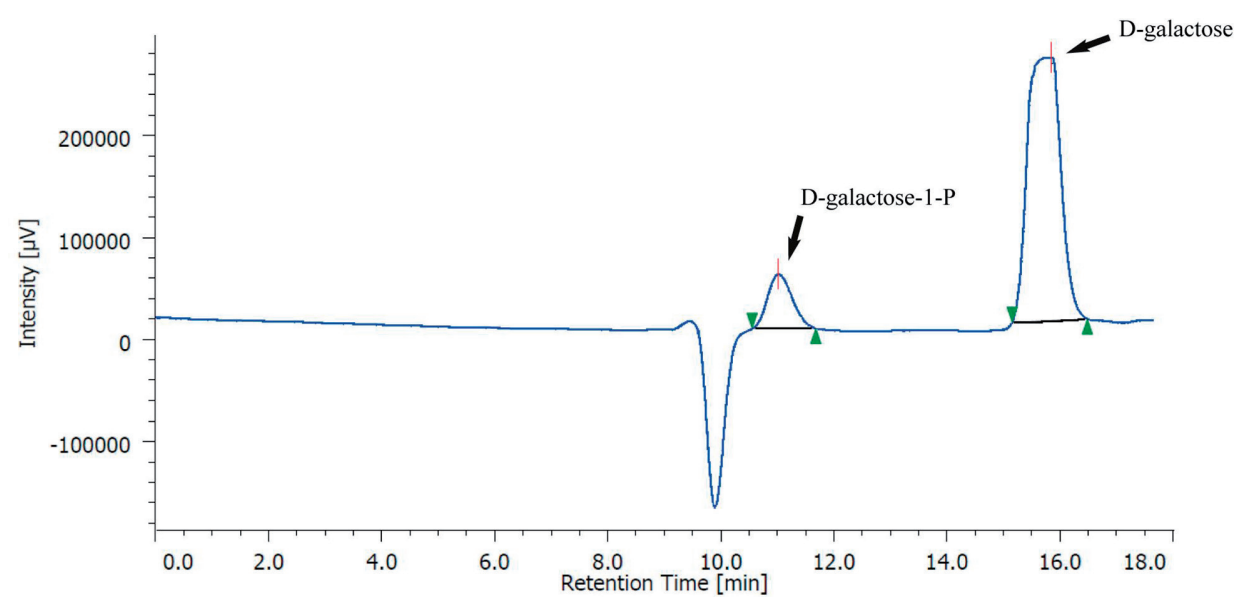

Fig. 2. A typical HPLC-chromatogram of a sample taken from the in vitro galactokinase assay reaction featuring clearly separated D-galactose-1-phosphate and D-galactose peaks 
(pH 7.6) was monitored with time, using High Performance Liquid Chromatography (HPLC) using a calibration curve of the phosphorylated sugar made in the same buffer. For the reader's convenience, Figure 2 shows a typical chromatogram with a clearly separated D-galactose-1-phosphate peak from a realtime sample.

\section{Analytical methods}

Mycelial dry cell weight (DCW) was determined from $5 \mathrm{ml}$ culture aliquots. The biomass was harvested and washed on a preweighted glass wool filter by suction filtration, washed with cold tap water and the filter dried at $80^{\circ} \mathrm{C}$ until constant weight. Dry weight data reported in the Results section are the average of the two separate measurements, which never deviated more than 14\%. D-Galactose was determined by HPLC with a proton exchange column (Bio-Rad Aminex HPX- $87 \mathrm{H}^{+}$; Bio-Rad, Berkeley, CA, USA) using isocratic elution with $10 \mathrm{mM} \mathrm{H}_{2} \mathrm{SO}_{4}$ at $55^{\circ} \mathrm{C}$ and refractive index detection.

\section{Reproducibility}

All the analytical and biochemical data presented are the means of three to five independent experiments (NB. Biological replicates). Data were analyzed and visualized with SigmaPlot software (Jandel Scientific, San Rafael, CA, USA), and for each procedure, standard deviations (SDs) were determined. The significance of changes in biomass and residual D-galactose as well as in galactose-1-phosphate concentrations in the growth medium relative to the control cultures was assessed using Student's $t$-test with probability $(p)$ values given in the Results section.

\section{Chemicals}

Except where specified, chemicals used in this study were of analytical grade and purchased from Sigma-Aldrich Kft. (Budapest, Hungary).

\section{RESULTS}

\section{Growth of Penicillium chrysogenum on D-galactose}

Conidiospores of several filamentous ascomycete fungi - a notable example is the cell factory Aspergillus niger - cannot germinate on D-galactose as a sole carbon source [15]. On the other hand, mycelia of these species are perfectly able to form new biomass from $\mathrm{D}$-galactose when germinated on other carbon sources. To verify whether the ability of $P$. chrysogenum to utilize D-galactose as a sole carbon source is growth-stage dependent or not, we inoculated conidiospores in liquid MM with 


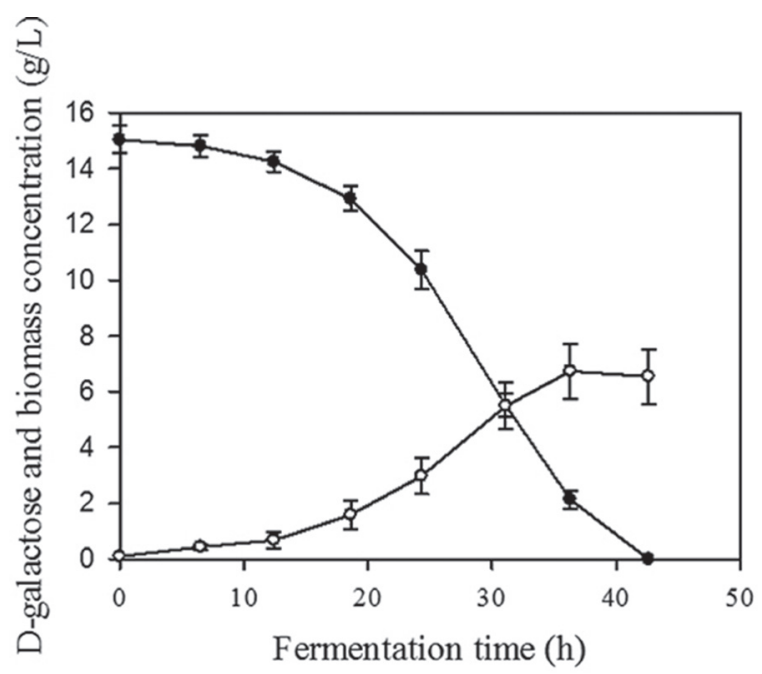

Fig. 3. Time-profile of growth (open symbols) as well as residual D-galactose concentrations (filled symbols) in batch fermentations of $P$. chrysogenum NRRL 1951. Medium was inoculated with conidiospores

$1.5 \% \mathrm{D}$-galactose as the sole carbon source. The fungus germinated in such submerged cultures and grew well on D-galactose, consuming $15 \mathrm{~g} / \mathrm{L}$ of the sugar in about $40 \mathrm{~h}$ (Fig. 3) and achieving a maximal specific growth rate of $\mathrm{m}_{\max }=0.085 \pm$ $0.006 \mathrm{H} / \mathrm{h}$ during the rapid growth phase. Maximal biomass concentration and the yield coefficient calculated from it were $\mathrm{X}_{\max }=6.73 \pm 0.49 \mathrm{~g} / \mathrm{L}$ and $\mathrm{Y}_{\mathrm{x} / \mathrm{s}}=0.45 \pm 0.04$, respectively.

In a parallel experiment, we germinated conidiospores of $P$. chrysogenum on glycerol and transferred pregrown mycelia to fresh medium containing D-galactose as a sole carbon source (data not shown). The replacement mode of cultivation resulted in essentially identical kinetic parameters as observed for the above cultures seeded with spore inoculum. In comparison, the respective parameters during submerged growth on D-glucose as a sole carbon source were $\mathrm{m}_{\max }=0.125 \pm 0.011 / \mathrm{h}, \mathrm{X}_{\max }=7.54 \pm 0.39$ $\mathrm{g} / \mathrm{L}$ and $\mathrm{Y}_{\mathrm{x} / \mathrm{s}}=0.51 \pm 0.04$. While these values are significantly $(p<0.1 \%)$ higher than those obtained for D-galactose, they show that D-galactose should nevertheless be considered a rapidly catabolized ('good') carbon source for $P$. chrysogenum. We would like to note that the presence of $0.01 \%$ peptone (i.e., $<1 \%$ of the initial D-galactose concentration) in the otherwise minimal medium considerably shortened the lag period at the onset of the conidiospore-inoculated submerged cultivation from approximately $20 \mathrm{~h}$ to approximately $4 \mathrm{~h}$, without significantly affecting the maximal growth rate in the rapid growth phase and regardless the sugar that served as the growth substrate. The phenomenon is likely related to an increased synchronization of the culture caused by the presence of small amounts of certain undefined components in bactopeptone that would effectively stimulate spore germination ([24] and references therein). 


\section{In silico identification of the Leloir pathway genes in P. chrysogenum}

The finding that $P$. chrysogenum can complete its (vegetative) life cycle on D-galactose as the sole carbon source suggested that the Leloir pathway is fully operative in the "catabolic" direction. It is not surprising, that in silico analysis revealed that the $P$. chrysogenum genome indeed specifies putative homologs for each of the five structural genes of this pathway (annotated loci in strain Wisconsin 54-1255 are listed Table 1), including ugeA encoding a singular 4-epimerase. This protein is highly similar to the N-terminal domain of the $S$. cerevisiae Gal10 bifunctional enzyme [27]. The corresponding ugeA gene in $A$. nidulans was studied previously for its anabolic function in providing the uridylylated galactose monomers for cell wall galactofurans [12]. UDP-hexose 4-epimerases often accept both UDP hexoses and their $N$-acetylated 2-amino forms as well as UDP-pentoses as their substrate (reviewed by [3]. In A. fumigatus, two structurally related UDP-hexose 4-epimerases were recently shown to be required for the synthesis of the galactosaminogalactan exopolysaccharide content of the fungal cell wall [26]. The weakly expressed $A$. nidulans gene for the paralog enzyme, $u g e B$, had been identified in an earlier work [32]. We included its $P$. chrysogenum ortholog as well as three additional autoannotated epimerase genes structurally related to A. nidulans loci AN0746 and AN3119 [17] in our current study to assess their possible role in Leloir catabolism of D-galactose next to ugeA. The mined P. chrysogenum genes for galactokinase ( $\mathrm{galE}$ ) and galactose-1-phosphate uridylyl transferase ( $\mathrm{galD}$ ) are the orthologs of the $A$. nidulans genes that are allelic to well-characterized, classically selected galactoseutilization mutations called galE9 and galD5, respectively [1, 35].



Fig. 4. Transcript analysis of the catabolic Leloir pathway genes in P. chrysogenum NRRL 1951. For experimental details, see the Materials and methods section. Gene abbreviations are according to Table 1. Ribosomal RNAs (28 S and $18 \mathrm{~S}$ ) were visualized in a $\%$ native agarose gel with ethidium bromide and shown as a quantitative and qualitative control of the RNA samples 


\section{Expression of the Leloir pathway on D-galactose and other sugars in $\mathrm{P}$. chrysogenum}

Expression studies were performed on D-galactose, the galactopyranose-containing disaccharide lactose and on the latter's other monomeric constituent, D-glucose. Also tested were the two most abundantly present pentoses in plant cell walls, L-arabinose and D-xylose.

All genes mined from the P. chrysogenum genome encoding the five structural enzymes of the Leloir pathway were expressed constitutively on D-galactose, irrespective of the time of sampling (i.e., 4, 8, 12 or $24 \mathrm{~h}$ after a medium shift of glycerol-pregrown mycelia; Fig. 4). For the putative 4-epimerase genes, the expression levels of ugeA appeared consistently considerably higher than those of ugeC. We could not detect transcript for the three other selected putative epimerase genes, uge $B$, $u g e D$ and $u g e E$, neither on D-galactose nor under any other of the tested growth conditions (results not shown). Essentially identical expression profiles were observed in the presence of lactose. Most importantly, however, the expression profiles of the studied genes on D-glucose, L-arabinose and D-xylose were markedly different from those apparent on D-galactose or lactose (Fig. 4). The genes coding for one of the UDP-D-galactose 4-epimerases (ugeA), the (putative) UDP-D-glucose pyrophosphorylase $(\mathrm{galF})$ and the phosphoglucomutase $(\mathrm{pgmA})$ were all expressed in a similar, principally constitutive fashion on these latter carbon sources, resembling their profiles in the presence of D-galactose or lactose as (sole) growth substrate. Their expression is very likely related to the essential anabolic functions of the Leloir pathway(s) in the synthesis of the fungal cell wall during growth until carbon source exhaustion (see Discussion section). On the contrary, transcripts of the first two genes of the catabolic Leloir pathway ( alE and galD) that - in theory - are irrelevant for cell wall synthesis on carbon sources other than D-galactose, could not be observed in our Northern analysis but - very modestly - at the last time point of the D-glucose induction experiment ( $24 \mathrm{~h}$ ), by which the growth substrate is completely exhausted (the latter, results not shown). Galactokinase enzyme activity determinations in biomass harvested after 10 and $24 \mathrm{~h}$ following medium transfer confirmed these transcript data (Table 2): very low activity could routinely be measured in D-glucosecultivated biomass $24 \mathrm{~h}$ after transfer, while at the earlier time point, only insignifi-

Table 2

Specific galactokinase activity of $P$. chrysogenum NRRL 1951 pre-grown on glycerol and subsequently transferred to a minimal medium containing one of various sugars

\begin{tabular}{|c|c|c|c|c|c|}
\hline \multirow{2}{*}{$\begin{array}{c}\text { Time lapse after } \\
\text { medium shift (h) }\end{array}$} & \multicolumn{5}{|c|}{ Carbon source } \\
\cline { 2 - 6 } & D-glucose & D-galactose & lactose & L-arabinose & D-xylose \\
\hline 10 & $>0.015$ & $0.350 \pm 0.04$ & $0.311 \pm 0.04$ & $>0.015$ & $>0.015$ \\
24 & $0.020 \pm 0.01$ & $0.321 \pm 0.03$ & $0.354 \pm 0.03$ & $>0.015$ & $>0.015$ \\
\hline
\end{tabular}

Specific activities are expressed in Units per mg protein. One Unit is defined as one microgram galactose1-phosphate formed per minute. 
cant $(p<0.1 \%)$ background was detected. Moreover, expression of either galE or galD could not be observed on L-arabinose and D-xylose with Northern analysis at any of the four time points of the transfer cultures of either pentose sugar, while no relevant galactokinase activities could be measured in pentose-cultivated mycelia (Fig. 4 and Table 2). Note that, in contrast to the D-glucose transfer, the cultures on the other four sugars were not carbon exhausted $24 \mathrm{~h}$ after medium transfer (results not shown). This suggests that the very modest expression of galE and galD observed in the D-glucose cultures $24 \mathrm{~h}$ after medium transfer (as certified by our galactokinase assays) is part of a starvation response in which reserve carbohydrate, including $\mathrm{D}$-galactose, is slowly liberated from the cell walls of the fungus. We conclude that the first two steps of the Leloir pathway of D-galactose catabolism are substrate inducible rather than constitutive in P. chrysogenum.

\section{DISCUSSION}

A number of Penicillium species including P. chrysogenum produce $\alpha$ - and $\beta$-glycosidase-like hydrolytic activities that enable the fungus to release D-galactose from plant cell wall polysaccharides as well as from lactose at rates suitable for applications in the biotech sector $[23,25]$. However, the ability of a fungus to release $\mathrm{D}$-galactose does not necessarily determine the rate at which the sugar is catabolized. This is for instance true for lactose utilization in A. nidulans where the uptake of the disaccharide rather than its hydrolysis is the rate limiting [16]. The majority of black Aspergilli, Aspergillus section Nigri, is unable to germinate on D-galactose [15]. However, our current investigation unequivocally demonstrates that $P$. chrysogenum is capable of using D-galactose as an energy, as well as a carbon source at every stage of growth, including the critical phase of spore germination.

While the role of the Leloir pathway with respect to D-galactose is catabolic, its epimerization into D-glucose before entering mainstream metabolism as glucose6-phosphate, part of it also functions as an essential anabolic pathway involved in vital areas of the intracellular carbohydrate metabolism, such as the biosynthesis of cell wall components, exopolysaccharides and lipopolysaccharides, for which uridylyl-activated glucose and -galactose are the necessary precursors [18]. In the absence of externally supplied D-galactose, the glucose/galactose Leloir pathway is the sole means to activate these monosaccharide building blocks for anabolic purposes starting from the key glycolytic intermediate glucose-6-phosphate. In A. nidulans, strains carrying allelic mutations at the classical locus pgmA resulting in complete or partial loss of phosphoglucomutase activity have been described to produce wild-type levels of UDP-glucose pyrophosphorylase, further suggesting that they affect only one structural gene [5]. These conditionally-lethal mutants could only grow in the presence of externally supplied D-galactose and an independent carbon source, indirectly demonstrating that the essential uridylylated monosaccharide cell wall precursors are produced uniquely from D-galactose in these strains. 
Of the five uge genes encoding putative nucleoside-diphosphate-sugar 4-epimerases, we found two that were expressed under the conditions tested. The ortholog of the A. nidulans ugeA gene (P. chrysogenum locus Pc21g10370) was always prominently expressed, including in the presence of $\mathrm{D}$-galactose or lactose. ugeC (Pc18g01080; corresponding to A. nidulans locus AN3119) transcript could also be observed regardless of carbon source or culture age, albeit at a considerably lower basal level. However, the ugeC gene appears to respond to L-arabinose as well as to D-glucose in the rapid growth phase $(12 \mathrm{~h})$, an expression profile that seems inconsistent with a prominent role in D-galactose catabolism, although we cannot exclude the possibility that extant $\mathrm{UgeC}$ protein is accessory to UgeA when catabolizing D-galactose.

In ascomycete filamentous fungi investigated to date, the five designated Leloir pathway genes were always found expressed when assessed by Northern analysis. Basal level expression was also observed for the galactokinase- and galactose-1-P uridylyltransferase encoding genes on carbon sources unrelated to D-galactose metabolism, while their transcript levels appeared to further increase in the presence of direct or indirect substrates of the catabolic Leloir pathway [7, 15, 38, 39]. Our finding that the galactokinase- and galactose-1-P uridylyltransferase encoding genes appeared selectively inducible to high levels by D-galactose and lactose in P. chrysogenum without featuring the basal constitutive expression levels evident in two other fungi commonly employed in the fermentation industry - A. niger and $T$. reese - may point towards hitherto unsuspected regulatory mechanisms. The remaining three structural genes of the Leloir pathway, pgmA, galF and ugeA, were expressed constitutively throughout our work, as expected for genes necessary for the synthesis of the essential precursors of the fungal cell wall, UDP-glucose and UDP-galactose.

Finally, we note that besides the Leloir pathway, fungal D-galactose catabolism can proceed via another route, the so-called alternative or oxido-reductive pathway. While the Leloir pathway is essentially ubiquitous in fungi and in the catabolic direction specific for D-galactose, the alternative pathway employs enzymes involved in L-arabinose catabolism up to the phosphorylation of D-xylulose (see [6], for L-arabinose catabolism in P. chrysogenum). Their involvement in fungal D-galactose utilization was first suggested in [9], and subsequently evidenced in D-galactokinasedeficient mutants in A. nidulans [14]. This study also showed that the use of the oxido-reductive path is dependent on the nature of the nitrogen source present. D-Galactose oxido-reductive catabolism also occurs in T. reesei [39] and A. niger [29]. However, in the two species of Aspergillus studied to date, the enzymes and intermediates in the route beyond L-arabitol dehydrogenase and its substrate D-galactitol are different [29]. Research is ongoing to see if and how the oxidoreductive pathway operates in $P$. chrysogenum D-galactose utilization.

\section{ACKNOWLEDGEMENTS}

The research was supported by the Hungarian Scientific Research Fund (OTKA NN116519). LK is a recipient of a Bólyai János Research Scholarship. The technical assistance of Dr. Norbert Ág is appreciated. 


\section{REFERENCES}

1. Alam, K., Kaminskyj, S. G. W. (2013) Aspergillus galactose metabolism is more complex than that of Saccharomyces: the story of GalD GAL7 and GalEGAL1. Botany 91, 467-477.

2. Altschul, S. F., Madden, T. L., Schäffer, A. A., Zhang, J., Zhang, Z., Miller, W., Lipman, D. J. (1997) Gapped BLAST and PSI-BLAST: a new generation of protein database search programs. Nucleic Acids Res. 25, 3389-3402.

3. Beerens, K., Soetaert, W., Desmet, T. (2015) UDP-hexose 4-epimerases: a view on structure, mechanism and substrate specificity. Carbohydrate Res. 414, 8-14.

4. Bhat, M. K. (2000) Cellulases and related enzymes in biotechnology. Biotechn. Adv. 18, 355-383.

5. Boschloo, J. G., Roberts, C. F. (1979) D-Galactose requiring mutants in Aspergillus nidulans lacking phosphoglucomutase. FEBS Lett. 104, 17-20.

6. Chiang, C., Knight, S. G. (1960) A new pathway of pentose metabolism. Biochem. Biophys. Res. Commun. 3, 554-559.

7. Christensen, U., Gruben, B. S., Madrid, S., Mulder, H., Nikolaev, I., de Vries, R. P. (2011) Unique regulatory mechanism for D-galactose utilization in Aspergillus nidulans. Appl. Environ. Microbiol. 77, 7084-7087.

8. Cragg, S. M., Beckham, G. T., Bruce, N. C., Bugg, T. D. H., Distel, D. L., Dupree, P., Etxabe, A. G., Goodell, B. S., Jellison, J., McGeehan, J. E., McQueen-Mason, S. J., Schnorr, K., Walton, P. H., Watts, J. E. M., Zimmer, M. (2015) Lignocellulose degradation mechanisms across the Tree of Life. Curr. Opin. Chem. Biol. 29, 108-119.

9. De Vries, R. P., Flipphi, M. J. A., Witteveen, C. F. B., Visser, J. (1994) Characterization of an Aspergillus nidulans L-arabitol dehydrogenase mutant. FEMS Microbiol. Lett. 123, 83-90.

10. De Vries, R. P., Visser, J. (2001) Aspergillus enzymes involved in degradation of plant cell wall polysaccharides. Microbiol. Mol. Biol. Rev. 65, 497-522.

11. Edson, C. M., Brody, S. (1976) Biochemical and genetic studies on galactosamine metabolism in Neurospora crassa. J. Bacteriol. 126, 799-805.

12. El-Ganiny, A. M., Sheoran, I., Sanders, D. A. R., Kaminskyj, S. G. W. (2010) Aspergillus nidulans UDP-glucose-4-epimerase UgeA has multiple roles in wall architecture, hyphal morphogenesis, and asexual development. Fungal Genet. Biol. 47, 629-635.

13. Fekete, E., Karaffa, L., Sándor, E., Seiboth, B., Biró, S., Szentirmai, A., Kubicek, C. P. (2002) Regulation of formation of the intracellular $\beta$-galactosidase activity of Aspergillus nidulans. Arch. Microbiol. 179, 7-14.

14. Fekete, E., Karaffa, L., Sándor, E., Bányai, I., Seiboth, B., Gyémánt G., Sepsi, A, Szentirmai, A., Kubicek, C. P. (2004) The alternative D-galactose degrading pathway of Aspergillus nidulans proceeds via L-sorbose. Arch. Microbiol. 181, 35-44.

15. Fekete, E., De Vries, R. P., Seiboth, B., Van Kuyk, P. A., Sándor, E., Fekete, E., Metz, B., Kubicek, C. P., Karaffa, L. (2012) D-galactose uptake is nonfunctional in the conidiospores of Aspergillus niger. FEMS Microbiol. Lett. 329, 198-203.

16. Fekete, E., Karaffa, L., Seiboth, B., Fekete, E., Kubicek, C. P., Flipphi, M. (2012) Identification of a permease gene involved in lactose utilisation in Aspergillus nidulans. Fungal Genet. Biol. 49, 415425 .

17. Flipphi, M., Sun, J., Robellet, X., Karaffa, L., Fekete, E., Zeng, A. P., Kubicek, C. P. (2009) Biodiversity and evolution of primary carbon metabolism in Aspergillus nidulans and other Aspergillus spp. Fungal Genet. Biol. 46, S19-S44.

18. Free, S. J. (2013) Fungal cell wall organization and biosynthesis. Adv. Genet. 81, 33-82.

19. Frey, P. A. (1996) The Leloir pathway: a mechanistic imperative for three enzymes to change the stereochemical configuration of a single carbon in galactose. FASEB J. 10, 461-470.

20. Haas, H., Angermayr, K., Zadra, I., Stöffler, G. (1997) Overexpression of nreB, a new GATA factorencoding gene of Penicillium chrysogenum, leads to repression of the nitrate assimilatory gene cluster. J. Biol. Chem. 272, 22576-22582. 
21. Houbraken, J., Frisvad, J. C., Samson, R. A. (2011) Fleming's penicillin producing strain is not Penicillium chrysogenum but $P$. rubens. IMA Fungus 2, 87-95.

22. Houbraken, J., Samson, R. A. (2011) Phylogeny of Penicillium and the segregation of Trichocomaceae into three families. Stud. Mycol. 70, 1-51.

23. Hu, X., Robin, S., O’Connell, S., Walsh, G., Wall, J. G. (2010) Engineering of a fungal $\beta$-galactosidase to remove product inhibition by galactose. Appl. Microbiol. Biotechnol. 87, 1773-1782.

24. Jónás, Á., Fekete, E., Flipphi, M., Sándor, E., Jäger, S., Molnár, Á. P., Szentirmai, A., Karaffa, L. (2014) Extra- and intracellular lactose catabolism in Penicillium chrysogenum: Phylogenetic and expression analysis of the putative permease and hydrolase genes. J. Antibiot. 67, 489-497.

25. Jørgensen, H., Mørkeberg, A., Krogh, K. B., Olsson, L. (2004) Growth and enzyme production by three Penicillium species on monosaccharides. J. Biotechnol. 109, 295-299.

26. Lee, M. J., Gravelat, F. N., Cerone, R. P., Baptista, S. D., Campoli, P. V., Choe, S. I., Kravtsov, I., Vinogradov, E., Creuzenet, C., Liu, H., Berghuis, A. M., Latgé, J. P., Filler, S. G., Fontaine, T., Sheppard, D. C. (2014) Overlapping and distinct roles of Aspergillus fumigatus UDP-glucose 4-epimerases in galactose metabolism and the synthesis of galactose-containing cell wall polysaccharides. J. Biol. Chem. 289,1243-1256.

27. Majumdar, S., Ghatak, J., Mukherji, S., Bhattacharjee, H., Bhaduri, A. (2004) UDPgalactose 4-epimerase from Saccharomyces cerevisiae: A bifunctional enzyme with aldose 1-epimerase activity. Eur. $J$. Biochem. 271, 753-759.

28. Milewski, S., Gabriel, I., Olchowy, J. (2006) Enzymes of UDP-GlcNAc biosynthesis in yeast. Yeast $23,1-14$

29. Mojzita, D., Koivistoinen, O. M., Maaheimo, H., Penttilä, M., Ruohonen, L., Richard, P. (2012) Identification of the galactitol dehydrogenase, $\mathrm{LadB}$, that is part of the oxido-reductive D-galactose catabolic pathway in Aspergillus niger. Fungal Genet. Biol. 49, 152-159.

30. Newbert, R. W., Barton, B., Greaves, P., Harper, J., Turner, G. (1997) Analysis of a commercially improved Penicillium chrysogenum strain series: Involvement of recombinogenic regions in amplification and deletion of the penicillin biosynthesis gene cluster. J. Ind. Microbiol. Biotechnol. 19, $18-27$.

31. Ozcengiz, G., Demain, A. L. (2013) Recent advances in the biosynthesis of penicillins, cephalosporins and clavams and its regulation. Biotechnol. Adv. 31, 287-311.

32. Paul, B. C., El-Ganiny, A. M., Abbas, M., Kaminskyj, S. G., Dahms, T. E. (2011) Quantifying the importance of galactofuranose in Aspergillus nidulans hyphal wall surface organization by atomic force microscopy. Eukaryot. Cell 10, 646-653.

33. Pauly, M., Keegstra, K. (2010): Plant cell wall polymers as precursors for biofuels. Curr. Opin. Plant Biol. 13, 305-312.

34. Raper, K. B., Alexander, D. F., Coghill, R. D. (1944) Penicillin. II. Natural variation and penicillin production in Penicillium notatum and allied species. J. Bacteriol. 48, 639-659.

35. Roberts, C. F. (1970) Enzyme lesions in galactose non-utilising mutants of Aspergillus nidulans. Biochim. Biophys. Acta 201, 267-283.

36. Sakamoto, T., Ishimaru, M. (2013) Peculiarities and applications of galactanolytic enzymes that act on type I and II arabinogalactans. Appl. Microbiol. Biotechnol. 97, 5201-5213.

37. Sambrook, J., Russell, D. W. (2001) Molecular Cloning: a Laboratory Manual (Cold Spring Harbor Laboratory, New York)

38. Seiboth, B., Hofmann, G., Kubicek, C. P. (2002) Lactose metabolism and cellulase production in Hypocrea jecorina: the gal7 gene, encoding galactose-1-phosphate uridylyltransferase, is essential for growth on galactose but not for cellulase induction. Mol. Genet. Genomics 267, 124-132.

39. Seiboth, B., Hartl, L., Pail, M., Fekete, E., Karaffa, L., Kubicek, C. P. (2004) The galactokinase of Hypocrea jecorina is essential for cellulase induction by lactose but dispensable for growth on D-galactose. Mol. Microbiol. 51, 1015-1025.

40. Wortman, J. R., Gilsenan, J. M., Joardar, V., Deegan, J., Clutterbuck, J., Andersen, M. R., Archer, D. Bencina, M., Braus, G., Coutinho, P., von Döhren, H., Doonan, J., Driessen, A. J., Durek, P., Espeso, E., Fekete, E., Flipphi, M., Garcia Estrada, C., Geysens, S., Goldman, G., de Groot, P. W., Hansen, 
K., Harris, S. D., Heinekamp, T., Helmstaedt, K., Henrissat, B., Hofmann, G., Homan, T., Horio, T., Horiuchi, H., James, S., Jones, M., Karaffa, L., Karányi, Z., Kato, M., Keller, N., Kelly, D. E., Kiel, J. A., Kim, J. M., van der Klei, I. J., Klis, F. M., Kovalchuk, A., Kraševec, N., Kubicek, C. P., Liu, B., MacCabe, A., Meyer, V., Mirabito, P., Miskei, M., Mos, M., Mullins, J., Nelson, D. R., Nielsen, J., Oakley, B. R., Osmani, S. A., Pakula, T., Paszewski, A., Paulsen, I., Pilsyk, S., Pócsi, I., Punt, P. J., Ram, A. F. J., Ren, Q., Robellet, X., Robson, G., Seiboth, B., van Solingen, P., Specht, T., Sun, J., Taheri-Talesh, N.,Takeshita, N., Ussery, D., van Kuyk, P. A., Visser, H., van de Vondervoort, P. J., de Vries, R. P., Walton, J., Xiang, X., Xiong, Y., Zeng, A. P., Brandt, B. W., Cornell, M. J., van den Hondel, C. A. M. J. J., Visser, J., Oliver, S. G., Turner, G. (2009) The 2008 update of the Aspergillus nidulans genome annotation: a community effort. Fungal Genet. Biol. 46, S2-S13. 